\title{
Perfect timing: Mobile brain/body imaging scaffolds the 4E-cognition research program
}

\author{
Francisco J. Parada ${ }^{1,2}$ (D) | Alejandra Rossi ${ }^{1,2}$ (i)
}

${ }^{1}$ Centro de Estudios en Neurociencia Humana y Neuropsicología, Facultad de Psicología, Universidad Diego Portales, Santiago, Chile

${ }^{2}$ Laboratorio de Neurociencia Cognitiva y Social, Facultad de Psicología, Universidad Diego Portales, Santiago, Chile

\section{Correspondence}

Francisco J. Parada, Laboratorio de Neurociencia Cognitiva y Social, Facultad de Psicología, Universidad Diego Portales, Vergara 275, 8370076 Santiago, Chile. Email: francisco.parada@udp.cl

\section{Funding information}

FJP is funded by FONDECYT Iniciación en Investigación project $N^{\circ} 11180620$. FJP and AR receive funding from Comisión Nacional de Investigación Científica y Tecnológica (CONICYT) by the Chilean Ministerio de Educación through their program Fondo Nacional de Desarrollo Científico y Tecnológico (FONDECYT) regular project $\mathrm{N}^{\mathrm{o}} 1190610$.

\begin{abstract}
Recent technological advancements encompassed under the Mobile Brain/Body Imaging (MoBI) framework have produced exciting new experimental results linking mind, brain and behaviour. Nevertheless, novel hypotheses, measures and experimental paradigms are needed in order to tackle MoBI's ultimate goal: to model and understand cognition, behaviour and experience as it emerges and unfolds unto and from the world. Such a goal is not completely novel or unique to the MoBI framework; it is at the core of a long-standing scientific and philosophical challenge. The ages-long debate revolves around the role of the body and the world on the emergence of the mind. Considering this, the present work has two goals. Our first goal is to briefly summarize some of the main ideas encompassed by the materialist/naturalist view of cognition as a complex emergent phenomenon. Our second and main goal is to argue that thanks to both MoBI and recent theoretical advances encompassed under the 4E-Cognition banner, theory and methodology might be finally synchronized, giving way to a revitalized form of emergentism, which lays new grounds for the understanding of cognitive phenomena. Finally, we offer the reader what we consider to be the main objective for the MoBI/4E framework and the understanding of the functional role of brain/body/world couplings in the emergence of cognition.
\end{abstract}

\section{K E Y W O R D S}

4E cognition, complexity, emergence, MoBI, naturalism

\section{1 | INTRODUCTION}

Recent technological advancements encompassed under the Mobile Brain/Body Imaging (MoBI) framework (Makeig, Gramann, Jung, Sejnowski, \& Poizner, 2009) have produced exciting new experimental results linking mind, brain and behaviour (Gramann, Ferris, Gwin, \& Makeig, 2014; Ladouce, Donaldson, Dudchenko, \& Letswaart, 2017; Shamay-Tsoory \& Mendelsohn, 2019). The main goal of the MoBI approach is to model brain

\footnotetext{
Abbreviations: 4E-Cognition, Embodied, Extended, Embedded and Enactive approach to Cognition; EED, Spanish abbreviation of "experiments scalable in their design" (experimentos escalables en su diseño), a suggested heuristic for MoBI/4E experiments; EEG, electroencephalography; EEG/HRV, concomitant measure of electroencephalography and heart rate variability; HRV, heart rate variability; MoBI/4E, the organic epistemic/methodological communion between Mobile Brain/Body Imaging and the Embodied, Extended, Embedded, and Enactive approach to Cognition, leading to novel transdisciplinary programs; MoBI, mobile brain/body imaging.

Edited by John Foxe
}

The peer review history for this article is available at https://publons.com/publon/10.1111/ejn.14783

(C) 2020 Federation of European Neuroscience Societies and John Wiley \& Sons Ltd 
and body dynamics during everyday, natural, real-life situations. However, even though considerable advances have been made in both hardware and software (Blum, Jacobsen, Bleichner, \& Debener, 2019; Debener, Emkes, De Vos, \& Bleichner, 2015; Ojeda, Bigdely-Shamlo, \& Makeig, 2014), technical and analytical conditions are not yet optimal (Gramann et al., 2014; Ladouce et al., 2017; Matusz, Dikker, Huth, \& Perrodin, 2019; Parada, 2018). The MoBI approach is based on attaching synchronized, small and lightweight neurobehavioural sensors to and around participants during behaviourally measured structured, semi-structured and unstructured settings (Gramann et al., 2014; Parada, 2018). These sensors have yet to become fully unobtrusive or transparent (Bleichner \& Debener, 2018; Debener et al., 2015). Even though a considerable technical and analytical gap still exists, acquisition of brain/body dynamics during real-world situations (Nann, Cohen, Deecke, \& Soekadar, 2019; Piñeyro Salvidegoitia et al., 2019; Rodríguez et al., 2018; Zink, Hunyadi, Van Huffel, \& Vos, 2016) as well as in virtual, modified and/ or extended laboratory settings has been-in many casessuccessful (Djebbara, Fich, Petrini, \& Gramann, 2019; Gramann, Gwin, Bigdely-Shamlo, Ferris, \& Makeig, 2010; Jungnickel \& Gramann, 2016; Soto et al., 2018).

Nevertheless, even if the technical/analytical gap is breached, novel hypotheses, measures and experimental paradigms are needed in order to tackle MoBI's ultimate goal: to model and understand cognition, behaviour and experience as it emerges and unfolds unto and from the world (Gramann et al., 2014; Krakauer, Ghazanfar, GomezMarin, MacIver, \& Poeppel, 2017; Makeig et al., 2009; Palacios-Garcia \& Parada, 2019; Parada \& Rossi, 2018). Such a goal is not completely novel or unique to the MoBI framework; it is at the core of a long-standing scientific and philosophical challenge. The ages-long debate revolves around the role of the body and the world on the emergence of the mind (Clark, 2008; de Condillac, 1793; MerleauPonty, 1976; Plato, 1911; Spinoza \& de Spinoza, 1985). Considering this, the present work has two goals. Our first goal is to briefly summarize some of the main ideas encompassed by the materialist/naturalist view of cognition as a complex emergent phenomenon. The goal of such brisk revision is to provide the context for the identification of three historical waves of complexity. Considering that the concept of emergence in philosophy is highly controversial (Blank, 2018; Gibb, Hendry, \& Lancaster, 2019; Kim, 2011; Murphy, 2016), discussing the existence of emergent properties or their constitutional characteristics exceeds both the goals of the current special edition and the present work. Hence, we will provide the reader with an idealized version of the historical development of the ideas composing emergent novelty from complex systems (Bedau \& Humphreys, 2008). After the brief historical review, we will argue that one could identify three "waves and ripples of complexity" derived from naturalist accounts to the historical brain/body problem.

Our second and main goal is to argue that thanks to both MoBI and recent theoretical advances encompassed under the Embodied, Extended, Embedded, and Enactive approach to Cognition (4E-Cognition) banner, theory and methodology might be finally synchronized. Giving way to a revitalized form of emergentism and offering new grounds for the understanding of cognitive phenomena. Even though "4E Cognition" might seem like an effort towards epistemic homogenization, the approach's strength lies in its complexity and heterogeneity. It is an approach that "does justice" to the complexity of the mind (Menary, 2010, p. 461) by considering multiple dimensions, levels and temporalities in which cognitive processes unfold and develop. This complexity is encompassed within each "E": Embodiment reframes mental representations of the world, providing corporal fulfilment of actions within specific ecological niches through time with a constitutive role in cognitive processes. That is, the body and the (neuro)physiological states emerging from its being-in-the-world are mechanically and constitutively linked to experience (Varela, Thompson, \& Rosch, 1991). If cognition is situated in the body and the body is situated in the world, the mind should be studied considering its ecological niche (Krakauer et al., 2017). Hence, cognition is always Embedded in context; the natural and built environment thus facilitates meaningful interaction and relational possibilities for action. Thus, if the environment affords behaviour and sense-making, in time, cognition is Extended beyond the body, incorporating both the physical and socio-cultural worlds into larger arcs of contextualized perception-action spatio-temporal couplings (Clark, 2013). Thus, when the scientist of the mind asks her fundamental question "how does a mind work?" considering the deep implications of the first three Es, she is left with one larger inevitable question: how can a mind emerge at all in the natural world? This is known as the "life-mind continuity hypothesis" (Jonas, 1966; Varela et al., 1991) and corresponds to the ontologic core of the Enactive perspective (Froese \& Di Paolo, 2011), with deep implications (Allen \& Friston, 2018; Constant, Badcock, Kirchhoff, $\&$ Friston, 2019). Summarizing, the 4E approach defines cognition as the emergent result of complex multi-scale interactions in time, which can be understood by relatively independent disciplinary scientific work on physical/biological, psychological and social processes, along with the resulting future transdisciplinary efforts.

Finally, we offer the reader what we consider to be the main objective for the MoBI + 4E framework in its quest for understanding the functional role of brain/body/world couplings in the emergence of cognition. 


\section{2 | NOVEL OLDNESS OR ANCIENT NOVELTY? WAVES AND RIPPLES OF COMPLEXITY}

One of the longest-standing philosophical problems revolves around the role of the body and the world in both the constitution and operation of the mind. Common solutions addressing this problem tend towards anthropocentrism and the supernatural (Boudry \& Coyne, 2016; Inagaki \& Hatano, 1999). Even though this kind of thinking dominates common belief, naturalist accounts can nevertheless be found throughout history. Naturalist accounts of the mind are often discussed in the context of emergentism and/or panpsychism. ${ }^{1}$ Many different versions of these can be found in the literature, and providing a deep and rigorous definition of both concepts is not the goal of this special edition and would fall outside the scope of the present work (for in-depth revisions, see Bedau \& Humphreys, 2008; Clarke, 2004). Thus, in order to reach our first goal and develop our argument preserving "metaphysical economy," we will situate ourselves within physicalist emergentism ${ }^{2}$ over panpsychism (for an account of emergentist panpsychism, see Seager, 2012). We chose physicalist emergentism given that cognition is a biophysical phenomenon. However, it is not property of the material understood as inert and immovable; it is a property of the material in time. Ontogenetic and phylogenetic trajectories through time allow for special configurations/states of the biophysical, leading to functional and structural novelty. These novel features of biological processes can only arise under certain states/configurations. We will understand those novel biological features as an emergent.

\section{1 | The first wave of complexity: ancient roots of emergentism}

Although early explanations of the mind are deeply rooted in the supernatural, naturalist accounts can also be found in the work of ancient free-thinkers. We consider naturalism at the core of emergentism. There is evidence to think that naturalist thinkers have endorsed what we can now think of

\footnotetext{
${ }^{1}$ We understand both panpsychism and emergentism as metaphysical accounts of complexity regarding the mind. Briefly, panpsychism asserts that mental properties suffuse the physical world. In contrast, emergentism posits that mental properties can only appear given certain types of complexity characterized by specific and special states, organizations and/ or dynamics of a system.

${ }^{2} \mathrm{We}$ will adopt a physicalist view of emergentism in order to argue that the occurrence of specific/special states, organizations and/or dynamics of a system will give rise to relevant and novel entities/causal powers. These must be physical, hence measurable and leaving no room for Cartesian dualism.
}

emergentist views. For example, Indian physicalism (circa 1,500 BCE) conceptualizes the human experience as rooted in the material body, leaving no room for anything else (Bhattacharya, 2002). That is, from the interaction of the material components of the body, reason, intelligence, thought and consciousness would arise. In the light of modern naturalist thinking, it has been argued that ancient Indian physicalism defines mental properties as emergent (Ganeri, 2011).

A naturalist account of cognition can also be found at the beginnings of classical Western philosophy. For examplealthough he ultimately rejects the idea-Socrates holds the possibility that some mental processes might be explained solely on bodily processes (Caston, 1997). Such processes are what he refers to as "passions," such as anger or fear. Socrates argues that, sometimes, external stimuli or reason fail to determine our mental states given the "passionate" state of the body. That is, if the body's current state is one of "anger," the mind will react with anger to stimuli that otherwise would not have been treated as such (Caston, 1997). Actually, Socrates erred by rejecting his own conjecture. Recent and growing evidence suggests that states of the body are determinants and mediators of mental states (Berger et al., 2019). Furthermore, Caston (1997) has argued that some neo-Aristotelians such as Alexander ( 200 AD) and Galen (130 AD-210 AD) can also be thought of as early emergentists. For neurosciences, Galen - as a pioneer in lesion studies and neuropsychologyis a very relevant historical figure, so we will use him as an example (Rocca, 1998). In modern terms, Galen argues that cognitive/mental states are the result of the organization of physical bodies through ontogeny (i.e. "after appropriate treatment and training," Caston, 1997, p. 353).

Similar debates and arguments can be found in early modern philosophy. For example, Spinoza sustains the mind and the body are constitutively the same, differing only in their dynamics (Bennett, 1981; Spinoza \& de Spinoza, 1985). In a similar fashion, de Condillac claimed that all of the mind's properties are acquired through sensorial experience in the world (de Condillac, 1793; Richards, 1979). Considering these accounts, we argue that throughout history, ideas derived from naturalism/physicalism can be considered as the ancient roots of emergentism.

\subsection{The second wave of complexity: British emergentism}

Even though the term "emergentism" was coined by this group of philosophers, we consider British emergentism as the second wave of complexity. In this period arises the first formal theoretical approach to give an answer to the question whether or not the constitutive elements and principles of biology were reducible to those of physics and/or chemistry (Gibb et al., 2019). From this tradition, British philosophers 
developed a theoretical argumentation in which the vital substances are avoided, but some of the irreducibly vital qualities or processes are conserved. Hence, British emergentism understands the world in layers, where each science describes a range of causal powers that emerge from-but are irreducible to-the causal powers of physical particles. Classic emergentism positions each layer in increased organizational complexity of matter, each studied by different disciplinary efforts. The first layer is physics, followed by chemistry, biology and other social sciences (such as psychology or sociology). In this layout, the sciences become increasingly specialized. Physics, at the base, shall investigate the underlying properties of the elementary constituents of nature and the laws that define them. Hence, other disciplines need to clarify the properties of complex material substances and the laws governing their characteristic behaviour and interactions (Ganeri, 2011; Gibb et al., 2019).

From the many implications of emergentist ideas (for an updated perspective, see Gibb et al., 2019), the relationship between levels is of prime interest to a neuroscientist and to the present work. Among the British tradition, it has two main different accounts, one by J.S. Mill and C.D. Broad, and the other by S. Alexander. To the former, rudimentary high-level interactions are generated in the more basic levels. Alexander, on the other hand, argues for the appearance of novel qualities and high-level causal patterns that cannot be directly expressed in terms of the entities and principles that are at the base. That is, although emergent qualities form a new kind, the world's fundamental dynamics stay the same (McLaughlin, 2008; Stephan, 1992). British emergentism attempted to explain the existence and the need of many sciences and its interactions at their different levels, rather than just one. The final thesis is that nature entails a hierarchical structure that is governed, in part, by autonomous laws of nature. British emergentism's thesis of trans-ordinal laws encompassed all sciences. It was a sort of "Theory of Everything," finally eroded by empirical evidence and the epistemic turn into behavioural reductionism that reigned during the first half of the 20th century (McLaughlin, 2008, 2019; Varela, 1992).

\subsection{The third wave of complexity: Cognition regains its body}

The second half of the 20th century provided a more suitable socio-cultural context for complexity within scientific thinking. It can be argued that such a background was laid by the epistemic debate between the behaviourist and cognitivist approaches to cognition (Gardner, 1987; Varela, 1992). Given its tendency towards internalist explanations, "good old-fashioned cognitive science" laid suitable grounds for debating the nature of cognition. Among the elements for debate during this period, the ages-long discussion on the role of both body and environment on the mind was prominent. ${ }^{3}$

We identify a third wave of complexity unfurling during the 1990s from multidisciplinary efforts over the two previous decades, ${ }^{4}$ remarking both the complexity of biological systems and the relevance of interaction between organisms and environment (Bonner, 1988; Freeman, 1975; Maturana \& Varela, 1972; Rogoff \& Lave, 1984). ${ }^{5}$ Thus, the third wave revitalized ideas developed primarily during the first half of the 20th century, upgrading them to mainstream philosophy of mind (Brentari, 2015; Gibson, 2015; MerleauPonty, 1976). ${ }^{6}$ Some of the most relevant concepts included that of the "enactive mind," emphasizing the dynamic relationship between mind, body and environment (Varela et al., 1991), the "extended mind" which accentuates the connection between cognitive agents and the world (Clark \& Chalmers, 1998; Flor \& Hutchins, 1991), and the "mind as a dynamic system" where cognition emerged as complexity increased throughout ontogeny (Thelen \& Smith, 1996). These revamped, updated and novel ideas laid the foundations to develop a naturalist, complex, dynamic and mechanistic understanding of the mind. Furthermore, although technological and scientific advancements have always been coupled and potentiating each other (Piccolino, 1998), the technological neuroimaging revolution during the "decade of the brain" opened never-imagined novel research pathways. Thus, the 21 st century neuroscientist has the much requested (Bronfenbrenner, 1977; Brunswik, 1943; Neisser, 1976) and never-seen-before opportunity to explore cognition in its natural state.

\section{3 | A VIRTUOUS CIRCLE: FROM EPISTEMOLOGY TO METHODOLOGY AND BACK}

Through the expansion of what we called the "third wave," (a) the rigid division between organisms (i.e. black boxes) and their environments (i.e. provider of inputs,

\footnotetext{
${ }^{3}$ It is worth mentioning that both still are current topics of debate (e.g. Di Paolo, 2020).

${ }^{4}$ Which, in turn, started developing with Cybernetics and Norbert Wiener's "Cybernetics: Or Control and Communication in the Animal and the Machine" (1948) as a stepping stone.

${ }^{5}$ The english edition of Maturana \& Varela's "De Máquinas y Seres Vivos" (1972, Editorial Universitaria, Chile) can be found as an extended edition "Autopoiesis \& Cognition" (1980, D. Reidel Publishing Company, Holland).

${ }^{6}$ These ideas could be seen as a natural development from British emergentism, which was ultimately truncated by the rise and extent of reductionist behaviourism.
} 
recipient of outputs) dissolved. Likewise, (b) the discreteness of neurobiological operations (i.e. Fodorian modularity) was replaced by contextualized integration of brain/body/ environment functional couplings. Finally, (c) the passivity/reactivity of organisms (i.e. recipient of inputs, transmitter of outputs) was replaced by the activity of living agents, developing and operating on their subjectively constituted environments. Furthermore, the turn of the century saw the emergence of the modern conceptualization of "network," integrating influences ranging from mathematics (Ahujia, Magnanti, \& Orlin, 1993) and systems biology (Barabasi \& Albert, 1999; Barabási \& Oltvai, 2004; Kitano, 2002; Varela \& Coutinho, 1991) to sociology (Wasserman \& Faust, 1994; Watts, 2004) and neuroscience (Sporns, 2002; Varela, Lachaux, Rodriguez, \& Martinerie, 2001).

Thus, the 21st century begun with empirical and philosophical foundations allowing: (a) a holistic and integrative view of the brain, its components and the functional dynamics that makes its operation possible (Friston, 2000; Kitano, 2002; McIntosh, 2000; Sporns, Tononi, \& Kötter, 2005), (b) a quest for complex and dynamic post-reductionist mechanisms (Bechtel \& Abrahamsen, 2005; Bechtel \& Richardson, 1993; Craver, 2007), and (c) epistemological diversity allowing scientists to accept, enjoy and understand complexity while exploring the biophysics of human experience (Brooks, 1997; Clark, 1997, 2008; Rose, 1997). This novel perspective has recently been formalized within the so-called "4E approach to Cognition" (Kiverstein \& Clark, 2009; Menary, 2010; Newen, De Bruin, \& Gallagher, 2018).

Likewise, in the wake of the third wave, technological advances encompassed under the MoBI framework (Makeig et al., 2009) have produced exciting new experimental results linking mind, brain and behaviour (Gramann et al., 2014; Ladouce et al., 2017; Shamay-Tsoory \& Mendelsohn, 2019). Gramann et al. (2014) identify the main goal of MoBI as the quantification of "natural cognition in action." Furthermore, they position "action" as a central component of cognition in the wild, as it affords (a) selection of information, (b) continuous and/or intermittent manipulation of the environment, (c) dynamic and multimodal integration of information, (d) evaluation of behaviour and its environmental consequences, and (e) prediction of behaviour and its environmental consequences. Thus, as witnessed by the present special edition, we argue that the MoBI framework is not only epistemologically compatible with the 4E-cognition approach, but it also has the capacity to scaffold novel empirical research programs derived from it. The virtuous interplay between methodology and epistemology (MoBI/4E) will be crucial in formulating a viable theory of how the brain/body-inthe-world system (Rossi, Grasso-Cladera, Luarte, Riillo, \& Parada, 2019) operates through space and time.

\subsection{A fourth wave of complexity?}

So far we have argued that the current synchrony between the epistemological 4E approach and the MoBI methodological framework is product of a long history of materialist/ naturalist views of the mind, as the time-varying emergent of complex webs of interactions. The virtuous MoBI/4E interplay has profound implications for research, and we therefore claim that we identify a fourth wave of complexity. To conclude the present piece, from the many implications that can be identified (and have already been identified, e.g. Gramann et al., 2014; Ladouce et al., 2017; Makeig et al., 2009; Matusz et al., 2019; Parada, 2018; ShamayTsoory \& Mendelsohn, 2019), we will highlight what it isfor us-the defining feature of the fourth wave: the study of human interaction. We think human interaction should be studied in order to generate mechanistic models describing the global set of time-varying brain/body/world components and its relationships underlying particular neurobehavioural processes.

The MoBI framework alone allows researchers to $d e$ scribe changes in functional dynamics in natural or real-life environments (e.g. spatial context-mediated event-related potentials associated to episodic memory, as in Piñeyro Salvidegoitia et al., 2019), while the 4E approach allows theorizing what such dynamics might do (e.g. socially facilitated engagement situated in a classroom measured by multi-agent electroencephalography (EEG), as in Dikker et al., 2017). However, the fourth wave of complexity will furthermore require explaining how those functional dynamics propagate, process and integrate brain/body-in-the-world activity during a particular process within a particular environment. In order to generate such models, the $\mathrm{MoBI} / 4 \mathrm{E}$ program will have to implement appropriate data analyses, so mechanisms can be drawn from correlational-not causal-data sets. For example, linear modelling of neurobehavioural data might offer an opportunity to decompose a complex MoBI data set into weighted components (Parra, Spence, Gerson, \& Sajda, 2005; Pernet, Chauveau, Gaspar, \& Rousselet, 2011). The construction of functional networks is possible using these weights, linking the appropriate nodes (Sporns, 2010). These could be analysed using the ever-increasing battery of network measures (Rubinov \& Sporns, 2010), in order to-for example-identify statistically overrepresented regularities (i.e. motifs, Milo et al., 2002), and overconnected (i.e. rich clubs, Colizza, Flammini, Serrano, \& Vespignani, 2006) or overinterconnected nodes (i.e. diverse clubs, Bertolero, Yeo, \& D'Esposito, 2017). The repertoire of brain/body functional states during natural cognition is-for now-mostly unknown and probably quite large (Gramann et al., 2014; Parada \& Rossi, 2018; Shamay-Tsoory \& Mendelsohn, 2019). Hence, a safe first hypothesis would be that successful real-world human interaction is achieved with limited morphological 
states, while the diversity and number of functional states are maximized. Thus supporting a large repertoire of dynamic metastable brain/body states, synchronously -and diachronically- transmitting/receiving verbal/non-verbal/environmental information in real time. Using network measures in order to identify such "functional building blocks" emerging during specific interaction contexts/tasks is one of the initial MoBI/4E goals (Figure 1).

Furthermore, MoBI/4E, by nature, encompasses several types and levels of interactions (e.g. synchrony: brain, brain/body, dyad brain/body-to-brain/body, group brain/ body-to-brain/body, etc.). Hence, instead of independently analysing each level, eventually we will be able to analyse them in an integrated fashion. Modelling different interaction levels as networks has been formalized as "multiplex networks" (Kivelä et al., 2014). Using multiplex networks in order to consider the interplay between interaction levels/ types allows preserving the information embedded in the global quantified complex interaction (Kivelä et al., 2014) as well as observing novel dynamics (Gambuzza, Frasca, \& Gómez-Gardeñes, 2015 observed a special and unique dynamical state of synchrony). Once the brain/body/world multiplex model has been built using appropriately chosen edges and nodes, statistical regularities such as motifs (Battiston, Nicosia, Chavez, \& Latora, 2017) or core-periphery organizations (Battiston, Guillon, Chavez, Latora, \& Fallani, 2018) could be identified. Again, implementing this type of analysis approach could allow the identification of global functional topology models of the dyadic system-corresponding to multiplex networks-where multiple non-random processes interact, modulating and affecting each other in time.

Following García and Di Paolo (2018) and Parada and Rossi (2018), the psychotherapeutic relationship can be seen as fertile grounds for human interaction research and two-person neuroscience. Thus, a hypothetical example could be drawn using psychotherapy, where-traditionally-a therapist and a patient gather together in order to build a therapeutic relationship. We think psychotherapy can be a good setting for implementing MoBI/4E research programs (Parada, 2018), as it is a semi-structured and ecological interactional scenario generating positive impacts on symptom reduction and overall well-being (Cozolino, 2017). Furthermore, even though psychotherapy is a completely natural setting, it possesses favourable pre-established parameters such as (a) interactional hierarchy where the dyad is immersed in a differential power relationship, (b) low degrees of freedom regarding body movements during interaction, (c) length and location for sessions, and (d) identifiable clinically relevant meaningful interactional episodes (Tomicic et al., 2015). These and other naturally occurring controlled conditions position the psychotherapeutic setting in a very strategic position at the moment of studying cognition in the wild. We think one of the most relevant opportunities is the possibility to measure the beginning, development-and eventually the end-of a real relationship. Recently, different data sources have been recorded throughout and during psychotherapeutic interactions, including electrocardiography/respiration (Tschacher \& Meier, 2019), body movements (Ramseyer \& Tschacher, 2014) and EEG (Lecchi, da Silva, Giommi, \& Leong, 2019; Rodríguez et al., 2018). Hence, acquiring MoBI data during such naturalistic human interactions is of relevance for a future transdisciplinary effort because it opens the possibility to study not only synchronization dynamics but also the diachronic/longitudinal process of participatory sense-making that characterizes human cognition (De Jaegher \& Di Paolo, 2007). (a)

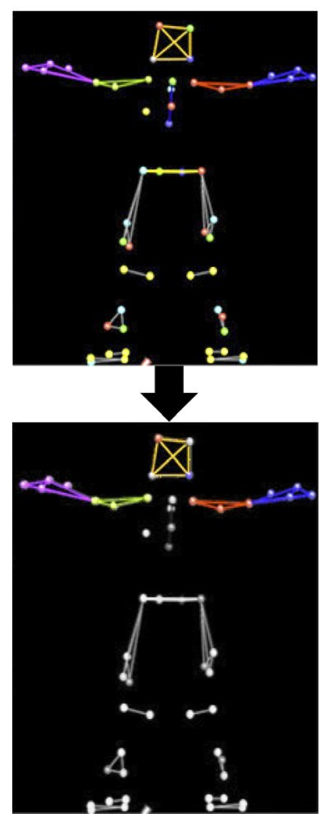

(b)

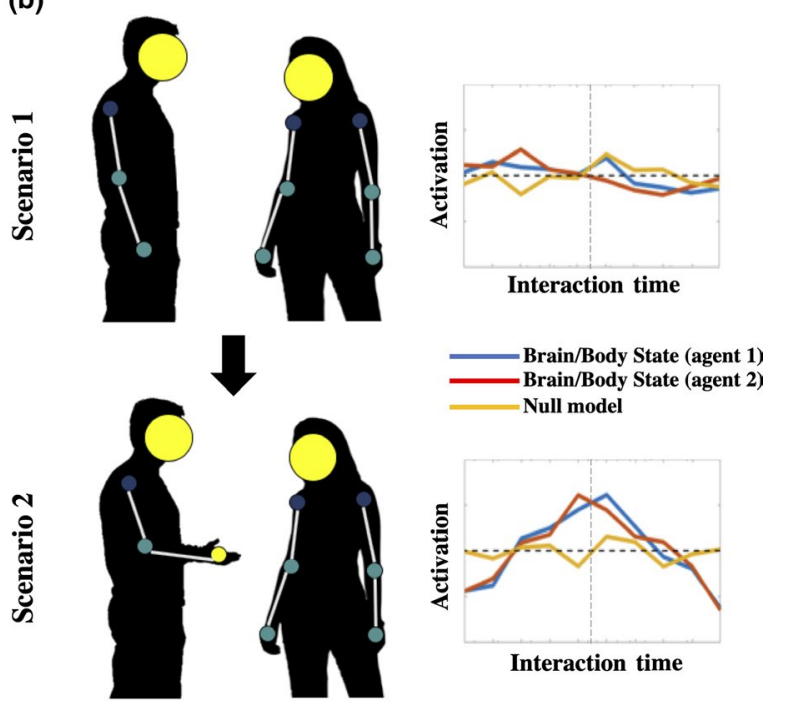

Interactional relevance

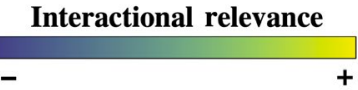

FIGURE 1 Hypothetical identification of brain/body states activation during interaction. (a) Top panel shows morphologically relevant body networks (Boonstra et al., 2015). Candidate interaction-relevant body networks (i.e. sets of nodes and edges) are selected in a hypothesis-driven fashion (e.g. arms and head/face, bottom panel). (b) Two agents interact in two different scenarios (left panels). Non-random interaction-relevant brain/body states are identified (right panels) 

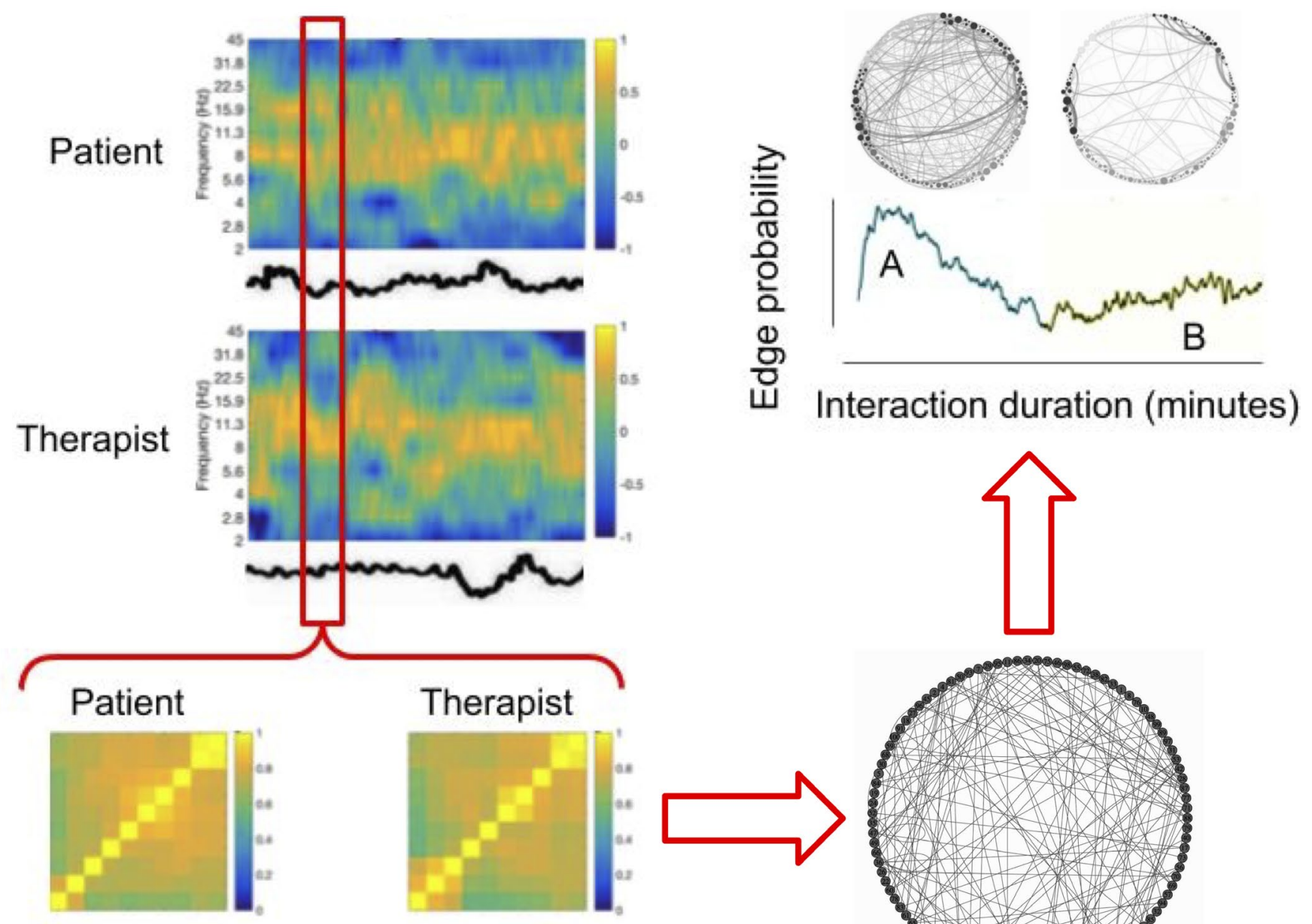

F I G U R E 2 Hypothetical construction of a patient/therapist interactome during psychotherapy. A multiplex network approach could be implemented to a complex MoBI data set in order to reduce dimensionality and uncover novel functional organizations with a potentially augmented understanding of natural interactions. For example, two "states" or structural organizations (a,b) could be identified during a period of psychotherapeutic interaction, where the patient/therapist system is modelled as a whole

Figure 2 shows EEG data with associated heart rate variability (HRV) for a patient and a therapist during relevant psychotherapeutic interactions. Time-windowed EEG/HRV correlation matrices could be obtained. Using appropriate thresholding methods (Sporns, 2010), supra-threshold correlated pairs could be then considered in order to build an $\mathrm{N}$-layer network corresponding to relevant dimensions (in this example, it could be a two-layer network, considering "rupture" and "change" types of interaction as in Tomicic et al., 2015. Temporal periods such as "first-half" and "second-half" of therapy could also be used in longitudinal recordings). This example suggests the possibility to infer novel functional structures in single- or multi-layer networks. Furthermore, these functional structures could be built using directed, non-directed, weighted, and time-varying data in order to identify state transitions or points of interactional change.

Furthermore, the results of these models can be taken back to laboratory settings in order to perform confirmatory experiments (Griffiths, 2015) and/or produce novel hypotheses to be taken back to real-world experiments (Parada, 2018). This strategy, based on the "experiments scalable in their design" $\left(\operatorname{EED}^{7}\right)$ heuristic, has already been suggested in the literature (Matusz et al., 2019; Parada, 2018; Shamay-Tsoory \& Mendelsohn, 2019), implemented empirically (Ladouce, Donaldson, Dudchenko, \& Ietswaart, 2019; Soto et al., 2018), and is a very promising approach.

\section{I CONCLUDING REMARKS}

We have identified three historical "waves of complexity" in order to provide a quick idea of the development

\footnotetext{
7“experimentos escalables en su diseño" in spanish.
} 
of a quest for complex and dynamic mechanisms that will support a holistic and integrative view of the brain/bodyin-the-world system. We furthermore suggest a fourth wave, emerging from the virtuous epistemological and methodological synchrony of the MoBI/4E interplay. This wave allows neuroscientists to accept, enjoy, explore and understand complexity underlying biophysics of human experience.

We think the generation of comprehensive mechanistic models of human interaction is the goal of this "fourth wave." Human interaction is essential for the development of natural cognition (Rogoff \& Lave, 1984). This global set of conditions were termed as "lifelines" by Rose (1997), we might even think of them as "lifestyles" (Lydon-Staley, Zurn, \& Bassett, 2019; Palacios-Garcia \& Parada, 2019; Sarkar et al., 2018; Tompson, Falk, Bassett, \& Vettel, 2019). Hence, MoBI/4E scientists will have the task to model individual and group brain/body dynamics as they unfold throughout specific periods of time (e.g. longitudinal recordings) and portions of space (e.g. built and natural environments), considering not only (neuro)physiological dynamics but also comparing and mapping people's subjectively constituted environments.

\section{ACKNOWLEDGEMENTS}

The authors would like to thank Dr. Daniel Rojas, Dr. Christian Salas and Dr. Ismael Palacios-García for relevant discussion during the writing of the present manuscript. We also like to thank Pascal Parada-Rossi for his enduring comprehension and support.

\section{CONFLICT OF INTEREST}

The authors declare that the research was conducted in the absence of any commercial or financial relationships that could be construed as a potential conflict of interest.

\section{AUTHOR CONTRIBUTIONS}

FJP conceptualized the present manuscript. FJP and AR wrote and edited the present manuscript for publication.

\section{ORCID}

Francisco J. Parada (iD https://orcid. org/0000-0002-8180-2026

Alejandra Rossi (D) https://orcid.org/0000-0003-1015-8402

\section{REFERENCES}

Ahujia, R. K., Magnanti, T. L., \& Orlin, J. B. (1993). Network flows: Theory, algorithms and applications. Englewood Cliffs, NJ: Rentice-Hall.

Allen, M., \& Friston, K. J. (2018). From cognitivism to autopoiesis: Towards a computational framework for the embodied mind. Synthese, 195(6), 2459-2482. https://doi.org/10.1007/s1122 9-016-1288-5
Barabasi, A. L., \& Albert, R. (1999). Emergence of scaling in random networks. Science, 286(5439), 509-512. https://doi.org/10.1126/ science.286.5439.509

Barabási, A.-L., \& Oltvai, Z. N. (2004). Network biology: Understanding the cell's functional organization. Nature Reviews Genetics, 5(2), 101-113. https://doi.org/10.1038/nrg1272

Battiston, F., Guillon, J., Chavez, M., Latora, V., \& Fallani, F. D. V. (2018). Multiplex core-periphery organization of the human connectome. Journal of the Royal Society, Interface, 15, 20180514. https://doi.org/10.1098/rsif.2018.0514

Battiston, F., Nicosia, V., Chavez, M., \& Latora, V. (2017). Multilayer motif analysis of brain networks. Chaos, 27(4), 047404. https://doi. org/10.1063/1.4979282

Bechtel, W., \& Abrahamsen, A. (2005). Explanation: A mechanist alternative. Studies in History and Philosophy of Biological and Biomedical Sciences, 36(2), 421-441. https://doi.org/10.1016/j. shpsc.2005.03.010

Bechtel, W., \& Richardson, R. C. (1993). Discovering complexity: Decomposition and localization as strategies in scientific research. Princeton, NJ: Princeton University Press.

Bedau, M. A., \& Humphreys, P. E. (2008). Emergence: Contemporary readings in philosophy and science. Cambridge, MA: MIT Press, https://psycnet.apa.org/record/2007-14527-000

Bennett, J. (1981). Spinosa's mind-body identity thesis. Journal of Philosophy, 78(10), 573-584. https://doi.org/10.5840/jphil19817 81024

Berger, J. M., Singh, P., Khrimian, L., Morgan, D. A., Chowdhury, S., Arteaga-Solis, E., ... Karsenty, G. (2019). Mediation of the acute stress response by the skeleton. Cell Metabolism, 30(5), 890-902. e8. https://doi.org/10.1016/j.cmet.2019.08.012

Bertolero, M. A., Yeo, B. T. T., \& D’Esposito, M. (2017). The diverse club. Nature Communications, 8(1), 1277. https://doi.org/10.1038/ s41467-017-01189-w

Bhattacharya, R. (2002). Cārvāka fragments: A new collection. Journal of Indian Philosophy, 30(6), 597-640. http://www.springerlink.com/ index/MX16K32012766M21.pdf

Blank, A. (2018). Sixteenth-century pharmacology and the controversy between reductionism and emergentism. Perspectives on Science: Historical, Philosophical, Social, 26(2), 157-184. https://doi. org/10.1162/POSC_a_00271

Bleichner, M. G., \& Debener, S. (2018). Towards transparent EEG: Ear-centered EEG acquisition using the cEEGrid. The Journal of the Acoustical Society of America, 143(3), 1744. https://doi. org/10.1121/1.5035692

Blum, S., Jacobsen, N. S. J., Bleichner, M. G., \& Debener, S. (2019). A Riemannian modification of artifact subspace reconstruction for EEG artifact handling. Frontiers in Human Neuroscience, 13, 141. https://doi.org/10.3389/fnhum.2019.00141

Bonner, J. T. (1988). The Evolution of complexity by means of natural selection. Princeton, NJ: Princeton University Press. https://play. google.com/store/books/details?id=IOU9DwAAQBAJ

Boonstra, T. W., Danna-Dos-Santos, A., Xie, H.-B., Roerdink, M., Stins, J. F., \& Breakspear, M. (2015). Muscle networks: Connectivity analysis of EMG activity during postural control. Scientific Reports, 5, 17830. https://doi.org/10.1038/srep17830

Boudry, M., \& Coyne, J. (2016). Disbelief in belief: On the cognitive status of supernatural beliefs. Philosophical Psychology, 29(4), 601-615. https://doi.org/10.1080/09515089.2015.1110852

Brentari, C. (2015). Jakob von Uexküll: The discovery of the Umwelt between biosemiotics and theoretical biology (Vol. 9). Springer. 
https://link.springer.com/content/pdf/10.1007/978-94-017-9688-0. pdf

Bronfenbrenner, U. (1977). Toward an experimental ecology of human development. The American Psychologist, 32(7), 513-531. https:// doi.org/10.1037/0003-066X.32.7.513

Brooks, R. A. (1997). Intelligence without representation. Cambridge, MA: MIT Press. https://books.google.com/books?hl=en\&l$\mathrm{r}=\& \mathrm{id}=\mathrm{D} 0 \mathrm{G} 56 \mathrm{Iu} 9 \mathrm{~W}$ sQC \&oi=fnd $\& \mathrm{pg}=\mathrm{PA} 235 \& \mathrm{dq}=+$ Intelligen ce+without+representation \&ots=zyvDutIOp3\&sig $=$ DQskX xuhZO3afgprqjFniIDoJlM

Brunswik, E. (1943). Organismic achievement and environmental probability. Psychological Review, 50(3), 255-272. https://doi. org/10.1037/h0060889

Caston, V. (1997). Epiphenomenalisms, ancient and modern. The Philosophical Review, 106(3), 309-363. https://doi. org/10.2307/2998397

Clark, A. (1997). Being there. Cambridge, MA: MIT Press. http:// mirror.macintosharchive.org/ca.cdn.preterhuman.net/texts/unsor ted2/Andy\%20Clark\%20-\%20Being\%20There\%20(Putting\%20Bra in,\%20Body\%20and\%20World\%20Together).pdf

Clark, A. (2008). Supersizing the mind: Embodiment, action, and cognitive extension. New York, NY: Oxford University Press. https:// market.android.com/details?id=book-n5wRDAAAQBAJ

Clark, A. (2013). Whatever next? Predictive brains, situated agents, and the future of cognitive science. The Behavioral and Brain Sciences, 36(3), 181-204. https://doi.org/10.1017/S0140525X1 2000477

Clark, A., \& Chalmers, D. (1998). The extended mind. Analysis, 58(1), 7-19. https://doi.org/10.1093/analys/58.1.7

Clarke, D. S. (2004). Panpsychism: Past and recent selected readings. Albany, NY: SUNY Press. https://play.google.com/store/books/ details?id=3GEe-jXC9scC

Colizza, V., Flammini, A., Serrano, M. A., \& Vespignani, A. (2006). Detecting rich-club ordering in complex networks. Nature Physics, 2(2), 110-115. https://doi.org/10.1038/nphys209

Cozolino, L. (2017). The neuroscience of psychotherapy: Healing the social brain, norton series on interpersonal neurobiology, 3edn, (1 -608). New York, NY: Norton Professional Books. https://books. google.cl/books?id=qtrTDgAAQBAJ.

Craver, C. F. (2007). Explaining the brain: Mechanisms and the mosaic unity of neuroscience. Oxford, UK: Clarendon Press. https://play. google.com/store/books/details?id=16IVDAAAQBAJ

de Condillac, E. B. (1793). Traité des sensations. chez les Librairies Associés. https://play.google.com/store/books/detai 1s?id=2VFA-aIrskkC

De Jaegher, H., \& Di Paolo, E. (2007). Participatory sense-making. Phenomenology and the Cognitive Sciences, 6(4), 485-507. https:// doi.org/10.1007/s11097-007-9076-9

Debener, S., Emkes, R., De Vos, M., \& Bleichner, M. (2015). Unobtrusive ambulatory EEG using a smartphone and flexible printed electrodes around the ear. Scientific Reports, 5, 16743. https://doi.org/10.1038/ srep16743

Di Paolo, E. A. (2020). Enactive becoming. Phenomenology and the Cognitive Sciences, 1-27. https://doi.org/10.1007/s11097-01909654-1

Dikker, S., Wan, L., Davidesco, I., Kaggen, L., Oostrik, M., McClintock, J., ... Poeppel, D. (2017). Brain-to-brain synchrony tracks real-world dynamic group interactions in the classroom. Current Biology, 27(9), 1375-1380. https://doi.org/10.1016/j.cub.2017.04.002
Djebbara, Z., Fich, L. B., Petrini, L., \& Gramann, K. (2019). Sensorimotor brain dynamics reflect architectural affordances. Proceedings of the National Academy of Sciences of the United States of America, 116(29), 14769-14778. https://doi.org/10.1073/ pnas.1900648116

Flor, N. V., \& Hutchins, E. L. (1991). A case study of team programming during perfective software maintenance. Empirical Studies of Programmers: Fourth Workshop, 36. https:// books.google.com/books ?hl=en\&lr=\&id=KT_bpSS J BgcC\&oi $=$ fnd \&pg $=$ PA36\&dq $=$ Flor,$+N .+$ V.,$+\% 26+$ Hutch ins, + E. + L. $+(1991) .+$ A +case + study + of + team + programmin $\mathrm{g}+$ during + perfective + software+maintenance. + Empirical + Studi es+of+Programmers:+Fourth+Workshop\&ots=xQqw7NoznB \&sig=aHyE-NDMJbvUH_PYPd-BQToWzKE

Freeman, W. J. (1975). Mass action in the nervous system. http:// citeseerx.ist.psu.edu/viewdoc/download?doi=10.1.1.465.2947 $\&$ rep $=$ rep1\&type $=$ pdf

Friston, K. J. (2000). The labile brain. II. Transients, complexity and selection. Philosophical Transactions of the Royal Society of London. Series B, Biological Sciences, 355(1394), 237-252. https://doi. org/10.1098/rstb.2000.0561

Froese, T., \& Di Paolo, E. A. (2011). The enactive approach: Theoretical sketches from cell to society. Pragmatics \& Cognition, 19(1), 1-36. https://doi.org/10.1075/pc.19.1.01fro

Gambuzza, L. V., Frasca, M., \& Gómez-Gardeñes, J. (2015). Intra-layer synchronization in multiplex networks. EPL, 110(2), 20010. https:// doi.org/10.1209/0295-5075/110/20010

Ganeri, J. (2011). Emergentisms, ancient and modern. Mind, 120(479), 671-703. https://doi.org/10.1093/mind/fzr038

García, E., \& Di Paolo, E. A. (2018). Embodied coordination and psychotherapeutic outcome: Beyond direct mappings. Frontiers in Psychology, 9, 1257. https://doi.org/10.3389/fpsyg.2018.01257

Gardner, H. (1987). The mind's new science: A history of the cognitive revolution. New York, NY: Basic books.

Gibb, S. C., Hendry, R., \& Lancaster, T. (2019). The Routledge handbook of emergence. London, UK: Routledge. https://content.taylorfrancis. com/books/download?dac $=$ C2015-0-59289-1\&isbn $=9781315675$ $213 \&$ format $=$ googlePreviewPdf

Gibson, J. J. (2015). The ecological approach to visual perception: Classic edition. New York, NY: Psychology Press. https:// content.taylorfrancis.com/books/download?dac $=$ C2013-0-26227 $-3 \&$ isbn $=9781317579380 \&$ format $=$ googlePreviewPdf

Gramann, K., Ferris, D. P., Gwin, J., \& Makeig, S. (2014). Imaging natural cognition in action. International Journal of Psychophysiology, 91(1), 22-29. https://doi.org/10.1016/j.ijpsycho.2013.09.003

Gramann, K., Gwin, J. T., Bigdely-Shamlo, N., Ferris, D. P., \& Makeig, S. (2010). Visual evoked responses during standing and walking. Frontiers in Human Neuroscience, 4, 202. https://doi.org/10.3389/ fnhum.2010.00202

Griffiths, T. L. (2015). Manifesto for a new (computational) cognitive revolution. Cognition, 135, 21-23. https://doi.org/10.1016/j.cogni tion.2014.11.026

Hesp, C., Ramstead, M., Constant, A., Badcock, P., Kirchhoff, M., \& Friston, K. (2019). A multi-scale view of the emergent complexity of life: A free-energy proposal. In G. Georgiev, J. Smart, C. Flores Martinez \& M. Price (Eds.), Evolution, development and complexity, springer proceedings in complexity, (195-227). Cham: Springer International Publishing. https://doi.org/10.1007/978-3-030-00075 $-2 \_7$ 
Inagaki, K., \& Hatano, G. (1999). Children's understanding of mindbody relationships. In Children's understanding of biology and health (pp. 23-44). https://books.google.com/books?hl=en\&l$\mathrm{r}=\& \mathrm{id}=52 \mathrm{Nm} \_$WEuw-UC\&oi=fnd $\& \mathrm{pg}=\mathrm{PA} 23 \& \mathrm{dq}=$ vitalism +mind + cognition \&ots $=$ CqDALVNbG7\&sig $=$ gofa8 $-1 \mathrm{~K} 34$ Spw $\mathrm{By} 2$ loFRP-gUY5w

Jonas, H. (1966). The phenomenon of life: Toward a philosophical biology. Evanston, IL: Northwestern University Press.

Jungnickel, E., \& Gramann, K. (2016). Mobile Brain/Body Imaging (MoBI) of physical interaction with dynamically moving objects. Frontiers in Human Neuroscience, 10, 306. https://doi.org/10.3389/ fnhum.2016.00306

Kim, J. (2011). From naturalism to physicalism: Supervenience redux. Proceedings and Addresses of the American Philosophical Association, 85(2), 109-134. http://www.jstor.org/stabl e/41575753

Kitano, H. (2002). Systems biology: A brief overview. Science, 295(5560), 1662-1664. https://doi.org/10.1126/science.1069492

Kivelä, M., Arenas, A., Barthelemy, M., Gleeson, J. P., Moreno, Y., \& Porter, M. A. (2014). Multilayer networks. Journal of Complex Networks, 2(3), 203-271. https://doi.org/10.1093/comnet/cnu016

Kiverstein, J., \& Clark, A. (2009). Introduction: Mind embodied, embedded, enacted: One church or many? Topoi, 28(1), 1-7. https:// doi.org/10.1007/s11245-008-9041-4

Krakauer, J. W., Ghazanfar, A. A., Gomez-Marin, A., MacIver, M. A., \& Poeppel, D. (2017). Neuroscience needs behavior: Correcting a reductionist bias. Neuron, 93(3), 480-490. https://doi.org/10.1016/j. neuron.2016.12.041

Ladouce, S., Donaldson, D. I., Dudchenko, P. A., \& Ietswaart, M. (2019). Mobile EEG identifies the re-allocation of attention during real-world activity. Scientific Reports, 9(1), 15851. https://doi. org/10.1038/s41598-019-51996-y

Ladouce, S., Donaldson, D. I., Dudchenko, P. A., \& Letswaart, M. (2017). Understanding minds in real-world environments: Toward a mobile cognition approach. Frontiers in Human Neuroscience, 10, 694. https://doi.org/10.3389/fnhum.2016.00694

Lecchi, T., da Silva, K., Giommi, F., \& Leong, V. (2019). Using dual-EEG to explore therapist client interpersonal neural synchrony. https://psyarxiv.com/ebkpv/download/?format=pdf

Lydon-Staley, D. M., Zurn, P., \& Bassett, D. S. (2019). Within-person variability in curiosity during daily life and associations with well-being. Journal of Personality, 77, 285. https://doi.org/10.1111/ jopy. 12515

Makeig, S., Gramann, K., Jung, T.-P., Sejnowski, T. J., \& Poizner, H. (2009). Linking brain mind and behavior. International Journal of Psychophysiology, 73(2), 95-100. https://doi.org/10.1016/j.ijpsy cho.2008.11.008

Maturana, H., \& Varela, F. J. (1972). De Máquinas y Seres Vivos: Una teoría sobre la organización biológica, 7edn, (1-140). Santiago, Chile: Editorial Universitaria S.A.

Matusz, P. J., Dikker, S., Huth, A. G., \& Perrodin, C. (2019). Are we ready for real-world neuroscience? Journal of Cognitive Neuroscience, 31(3), 327-338. https://doi.org/10.1162/ jocn_e_01276

McIntosh, A. R. (2000). Towards a network theory of cognition. Neural Networks, 13(8-9), 861-870. https://doi.org/10.1016/s0893 $-6080(00) 00059-9$

McLaughlin, B. P. (2008). The rise and fall of british emergentism. In Emergence (pp. 19-60). https://doi.org/10.7551/mitpress/97802 62026215.003 .0003
McLaughlin, B. P. (2019). British emergentism. In The Routledge handbook of emergence (pp. 23-35). https://doi.org/10.4324/97813 15675213-2

Menary, R. (2010). Introduction to the special issue on 4E cognition. Phenomenology and the Cognitive Sciences, 9(4), 459-463. https:// doi.org/10.1007/s11097-010-9187-6

Merleau-Ponty, M. (1976). Phénoménologie de la perception (1945). Libraqire Gallimard, Paris. http://perso.lcpc.fr/roland.bremond/ documents/MerleauPonty_intro.pdf

Milo, R., Shen-Orr, S., Itzkovitz, S., Kashtan, N., Chklovskii, D., \& Alon, U. (2002). Network motifs: Simple building blocks of complex networks. Science, 298(5594), 824-827. https://doi.org/10.1126/ science.298.5594.824

Murphy, N. (2016). Reductionism and emergence a critical perspective. In Human identity at the intersection of science, technology and religion (pp. 79-96). Routledge. https://www.taylorfrancis.com/books /e/9781315587431/chapters/10.4324/9781315587431-5

Nann, M., Cohen, L. G., Deecke, L., \& Soekadar, S. R. (2019). To jump or not to jump - The Bereitschafts potential required to jump into 192-meter abyss. Scientific Reports, 9(1), 2243. https://doi. org/10.1038/s41598-018-38447-w

Neisser, U. (1976). Cognition and reality: Principles and implications of cognitive psychology. 230. https://psycnet.apa.org/fulltext/200300066-000.pdf

Newen, A., De Bruin, L., \& Gallagher, S. (Eds.). (2018). The Oxford handbook of $4 E$ cognition. Oxford, UK: Oxford University Press.

Ojeda, A., Bigdely-Shamlo, N., \& Makeig, S. (2014). MoBILAB: An open source toolbox for analysis and visualization of mobile brain/ body imaging data. Frontiers in Human Neuroscience, 8, 121. https://doi.org/10.3389/fnhum.2014.00121

Palacios-Garcia, I., \& Parada, F. J. (2019). Measuring the brain-gut axis in psychological sciences: A necessary challenge. Frontiers in Integrative Neuroscience, 13(73), 1-7. https://doi.org/10.3389/ fnint.2019.00073

Parada, F. J. (2018). Understanding natural cognition in everyday settings: 3 pressing challenges. Frontiers in Human Neuroscience, 12, 386. https://doi.org/10.3389/fnhum.2018.00386

Parada, F. J., \& Rossi, A. (2018). If neuroscience needs behavior what does psychology need? Frontiers in Psychology, 9, 433. https://doi. org/10.3389/fpsyg.2018.00433

Parra, L. C., Spence, C. D., Gerson, A. D., \& Sajda, P. (2005). Recipes for the linear analysis of EEG. NeuroImage, 28(2), 326-341. https:// doi.org/10.1016/j.neuroimage.2005.05.032

Pernet, C. R., Chauveau, N., Gaspar, C., \& Rousselet, G. A. (2011). LIMO EEG: A toolbox for hierarchical LInear MOdeling of ElectroEncephaloGraphic data. Computational Intelligence and Neuroscience, 2011, 831409. https://doi.org/10.1155/2011/831409

Piccolino, M. (1998). Animal electricity and the birth of electrophysiology: The legacy of Luigi Galvani. Brain Research Bulletin, 46(5), 381-407. https://doi.org/10.1016/s0361-9230(98)00026 $-4$

Piñeyro Salvidegoitia, M., Jacobsen, N., Bauer, A.-K.-R., Griffiths, B., Hanslmayr, S., \& Debener, S. (2019). Out and about: Subsequent memory effect captured in a natural outdoor environment with smartphone EEG. Psychophysiology, 56(5), e13331. https://doi. org/10.1111/psyp.13331

Plato. (1911). Plato's Phaedo. Oxford, UK: Clarendon Press. Retrieved from https://search.library.wisc.edu/catalog/999866668102121

Ramseyer, F., \& Tschacher, W. (2014). Nonverbal synchrony of headand body-movement in psychotherapy: Different signals have 
different associations with outcome. Frontiers in Psychology, 5, 979. https://doi.org/10.3389/fpsyg.2014.00979

Richards, R. J. (1979). Influence of sensationalist tradition on early theories of the evolution of behavior. Journal of the History of Ideas, 40(1), 85-105. https://doi.org/10.2307/2709261

Rocca, J. (1998). Galen and Greek neuroscience. Early Science and Medicine, 3(3), 216-240. https://doi.org/10.1163/157338298X00158

Rodríguez, E., Martínez, C., Díaz, M., Flores, J., Alvarez-Ruf, J., Crempien, C., ... Tomicic, A. (2018). Neurodynamics inside therapeutic interaction: A case study with simultaneous EEG recording/ La neurodinámica en el contexto de la interacción terapéutica: Un estudio de caso con una grabación simultánea de EEG. Estudios De Psicología, 39(1), 179-204. https://doi.org/10.1080/02109 395.2017.1407902

Rogoff, B., \& Lave, J. (Eds.). (1984). Everyday cognition: Its development in social context. 314. Retrieved from https://psycnet.apa.org/ fulltext/1988-98320-000.pdf

Rose, S. P. R. (1997). Lifelines: Life beyond the gene. Oxford, UK: Oxford University Press. https://play.google.com/store/books/detai ls?id=oXk8DwAAQBAJ

Rossi, A., Grasso-Cladera, A., Luarte, N., Riillo, A., \& Parada, F. J. (2019). El sistema cerebro/cuerpo-en-el-mundo es el objeto de estudio de la ciencia cognitiva en el siglo XXI. Estudios De Psicología, 40, 363-395. https://doi.org/10.1080/02109395.2019.1596704

Rubinov, M., \& Sporns, O. (2010). Complex network measures of brain connectivity: Uses and interpretations. NeuroImage, 52(3), 10591069. https://doi.org/10.1016/j.neuroimage.2009.10.003

Sarkar, A., Harty, S., Lehto, S. M., Moeller, A. H., Dinan, T. G., Dunbar, R. I. M., ... Burnet, P. W. J. (2018). The microbiome in psychology and cognitive neuroscience. Trends in Cognitive Sciences, 22(7), 611-636. https://doi.org/10.1016/j.tics.2018.04.006

Seager, W. (2012). Emergentist panpsychism. Journal of Consciousness Studies, 19(9-10), 19-39. https://www.ingentaconnect.com/content/ imp/jcs/2012/00000019/f0020009/art00002

Shamay-Tsoory, S. G., \& Mendelsohn, A. (2019). Real-life neuroscience: An ecological approach to brain and behavior research. Perspectives on Psychological Science, 14(5), 841-859. https://doi. org/10.1177/1745691619856350

Soto, V., Tyson-Carr, J., Kokmotou, K., Roberts, H., Cook, S., Fallon, N., ... Stancak, A. (2018). Brain responses to emotional faces in natural settings: A wireless mobile EEG recording study. Frontiers in Psychology, 9, 2003. https://doi.org/10.3389/fpsyg.2018.02003

Spinoza, B., \& de Spinoza, B. (1985). The collected works of Spinoza (Vol. 1). Princeton, NJ: Princeton University Press.

Sporns, O. (2002). Network analysis, complexity, and brain function. Complexity, 8(1), 56-60. https://doi.org/10.1002/cplx.10047

Sporns, O. (2010). Networks of the brain. MIT Press. https://play.google.com/store/books/details?id=v1DBKE7-UrYC

Sporns, O., Tononi, G., \& Kötter, R. (2005). The human connectome: A structural description of the human brain. PLoS Computational Biology, 1(4), e42. https://doi.org/10.1371/journal.pcbi.0010042

Stephan, A. (1992). Emergence: A systematic view on its historical facets. In A. Beckermann, H. Flohr, \& J. Kim (Eds.), Emergence or reduction: Essays on the prospects of nonreductive physicalism (pp. 25-48). Berlin: Walter de Gruyter.
Thelen, E., \& Smith, L. B. (1996). A dynamic systems approach to the development of cognition and action (Vol. 7). MIT Press. https://doi. org/10.1162/jocn.1995.7.4.512

Tomicic, A., Martínez, C., Pérez, J. C., Hollenstein, T., Angulo, S., Gerstmann, A., ... Krause, M. (2015). Discourse-voice regulatory strategies in the psychotherapeutic interaction: A state-space dynamics analysis. Frontiers in Psychology, 6, 378. https://doi. org/10.3389/fpsyg. 2015.00378

Tompson, S. H., Falk, E. B., Bassett, D. S., \& Vettel, J. M. (2019). Using neuroimaging to predict behavior: An overview with a focus on the moderating role of sociocultural context. In P. K. Davis, A. O'Mahony, \& J. Pfautz (Eds.), Social-behavioral modeling for complex systems (Vol. 60, pp. 205-230). John Wiley \& Sons, Inc. https:// doi.org/10.1002/9781119485001.ch10

Tschacher, W., \& Meier, D. (2019). Physiological synchrony in psychotherapy sessions. Psychotherapy Research, 30(5), 558-573. https:// doi.org/10.1080/10503307.2019.1612114

Varela, F. J. (1992). Conocer: Las ciencias cognitivas: tendencias y perspectivas. Cartografía de las ideas actuales. Gedisa. http://www. sidalc.net/cgi-bin/wxis.exe/?IsisScript=UCC.xis\&method=post\&formato $=2 \&$ cantidad $=1 \&$ expresion $=m f n=054196$

Varela, F. J., \& Coutinho, A. (1991). Second generation immune networks. Immunology Today, 12(5), 159-166. https://doi.org/10.1016/ S0167-5699(05)80046-5

Varela, F. J., Lachaux, J. P., Rodriguez, E., \& Martinerie, J. (2001). The brainweb: Phase synchronization and large-scale integration. Nature Reviews Neuroscience, 2(4), 229-239. https://doi. org/10.1038/35067550

Varela, F. J., Thompson, E., \& Rosch, E. (1991). The embodied mind: Cognitive science and human experience. MIT Press https://play. google.com/store/books/details?id=gzLaDQAAQBAJ

Wasserman, S., Faust, K., \& Stanley (University of Illinois Wasserman, Urbana-Champaign). (1994). Social network analysis: Methods and applications. Cambridge University Press. https://play.google.com/ store/books/details?id=CAm2DpIqRUIC

Watts, D. J. (2004). The "new" science of networks. Annual Review of Sociology, 30(1), 243-270. https://doi.org/10.1146/annur ev.soc.30.020404.104342

Wiener, N. (1948). Cybernetics or control and communication in the animal and the machine, 2edn, (1-212). Cambridge, Massachusetts: The MIT Press.

Zink, R., Hunyadi, B., Van Huffel, S., \& Vos, M. D. (2016). Mobile EEG on the bike: Disentangling attentional and physical contributions to auditory attention tasks. Journal of Neural Engineering, 13(4), 046017. https://doi. org/10.1088/1741-2560/13/4/046017

How to cite this article: Parada FJ, Rossi A. Perfect timing: Mobile brain/body imaging scaffolds the 4E-cognition research program. Eur J Neurosci. 2020;00:1-11. https://doi.org/10.1111/ejn.14783 